\title{
Governance in the Internet of Vehicles (IoV) Context: Examination of Information Privacy, Transport Anxiety, Intention, and Usage
}

\author{
Hafezali Iqbal Hussain (D), 1,2 Fakarudin Kamarudin (iD, ${ }^{3,4}$ Zuraidah Mohd-Sanusi (iD, 5 \\ Shuhaida Mohamed Shuhidan $\left(10,{ }^{6}\right.$ Ahmed Abdullah Saad Al-Dhubaibi $\left(\mathbb{D},{ }^{7}\right.$ \\ and Mohd Shahril Ahmad Razimi $\oplus^{8}$ \\ ${ }^{1}$ Taylor's Business School, Taylor's University, 47500 Subang Jaya, Malaysia \\ ${ }^{2}$ University of Economics and Human Sciences in Warsaw, Okopowa, Warsaw, Poland \\ ${ }^{3}$ School of Business and Economics, Universiti Putra Malaysia, 43400 Serdang, Malaysia \\ ${ }^{4}$ Malaysia and EIS-UPMCS Centre for Future Labour Market Studies, SOCSO, Kuala Lumpur, Malaysia \\ ${ }^{5}$ Accounting Research Institute and Faculty of Accountancy, Universiti Teknologi MARA, 40450 Shah Alam, Selangor, Malaysia \\ ${ }^{6}$ Accounting Research Institute and Faculty of Computer Science and Mathematics, Universiti Teknologi MARA, \\ 40450 Shah Alam, Selangor, Malaysia \\ ${ }^{7}$ Department of Accounting, College of Business Administration, Prince Sattam Bin Abdulaziz University, 11942 Al-Kharj, \\ Saudi Arabia \\ ${ }^{8}$ Islamic Business School, Universiti Utara Malaysia, Sintok, 06010 Bukit Kayu Hitam, Malaysia
}

Correspondence should be addressed to Mohd Shahril Ahmad Razimi; razimimsa@gmail.com

Received 28 January 2021; Revised 15 March 2021; Accepted 29 March 2021; Published 24 April 2021

Academic Editor: Muhammad Arif

Copyright ( 2021 Hafezali Iqbal Hussain et al. This is an open access article distributed under the Creative Commons Attribution License, which permits unrestricted use, distribution, and reproduction in any medium, provided the original work is properly cited.

\begin{abstract}
This study examines the validity and acceptability of concern for information privacy with the Internet of vehicle context. For this purpose, the exploratory and confirmatory analysis processes were performed for testing the validity of concern for the Internet of vehicle information privacy. A total number of 357 responses were received online which were complete in all respects from college and university students studying information system course at undergraduate and graduate level. The estimated results obtained from exploratory and confirmatory factor analysis revealed that 3-dimension construct containing collection, error, and information accuracy measuring governance for Internet of vehicle information privacy (CFIOVIP) was validated through second order construction with strong goodness-of-fit estimates. The relevant factors were reliable and valid as per their internal and external validity estimates of Cronbach Alpha, average variance extracted, composite reliability, discriminant validity, and factor loading values including their fitness indices for 16 items for 3 -dimension construct of CFIOVIP. The findings of the study indicate that Internet of vehicle users view secondary usage of information and unauthorised access of information as the same dimension with the title of information access for measuring CFIOVIP along with two other constructs like collection and error in information for the Internet of vehicle context. The study recommends a $2^{\text {nd }}$ order CFIOVIP construct based on three dimensions, namely, collection, error, and information access, for testing the present governance of the Internet of vehicles.
\end{abstract}

\section{Introduction}

The modern age of the Internet of things has motivated the advancement of traditional Ad-hoc based network of vehicles into entirely a modern concept of the Internet of Vehicle. The
Internet of Vehicle concept has emerged as the greater research value with a major interest in commercial technologies and computation as the prompt development [1-3]. In recent years, programmes related to smart cities have grown rapidly and users are switching from central computers to 
community data centres. As a result, the transportation markets are urgently in need of strategies that can enhance driving safety, vehicle safety, and perhaps even the cost of reducing prices [4]. There is a related spike in the number of deaths caused by accidents when too many people drive automobiles and vehicles. Progressively linked to the Internet of Things (IoT), such automobiles create the Internet of Vehicles (IoV). The Internet of vehicle concept is the integration of IoT and Internet access for vehicles. For the motor industry, this is an emerging sector and an essential part of new technologies [5]. Today, IoT also makes it possible to connect cars, houses, and other objects equipped with sensors, electronic controls, and access points. The Network of Vehicles is known through the use of the Internet of Things (IoT). Similarly, the Internet of Vehicles (IoV) is used to create connectivity between objects, automobiles, and locations for the transmission between channels of data or information. [6]. Each automobile is conceived as just an autonomous object, configured with sensor applications, computer equipment, control units, including storage areas, as well as linked through vehicle-to-everything connectivity to any individual. Intelligent vehicles will take on multiple tasks, i.e., also being a customer and a database, taking and distributing big data resources, leading to several new applications, through aided driving through platooning, a safe collaboration of knowledge to vehicle control and implementation [7].

The proliferation of social media rewards individuals as well as organizations with unparalleled confidential information which was once difficult to obtain. Doubtlessly, privacy issues are becoming critically relevant on social networking sites as vendors also can eventually obtain access to a broad disclosure of personal data from users [8]. Various stakeholders, particularly corporate leaders, privacy advocates, academics, government officials, and individual users, are increasingly concerned about data privacy. Surveys show that Internet users are highly worried and confirm that privacy is the highest concern for corporations [9]. Privacy problems did not forecast Smartphone usage, inconsistent with the position including its privacy issue. Users concerned with privacy, nonetheless, were less likely to utilize resources and exchange information and were much more inclined to use precautions to protect confidentiality. Except for exchanging information, the interactions were equivalent in terms of intentions and behaviour [10]. Sharing is correlated with distinct types to privacy concerns relative to more conventional web services, which could exacerbate the degree of privacy concerns, requiring clear theoretical reasons for the sharing actions of users amid privacy concerns $[11,12]$. A key concern of the digital world is privacy. Advancement in information and communication technology (ICTs), as well as their broad acceptance, has increased the quantity of private information gathered by business and government agencies exponentially. While ICTs including fitness apps, headphone amplifiers, as well as social networks give alternative ways for users to connect and learn regarding themselves; these also present a variety of hazards to privacy [13].
Privacy is not a concern if individuals were not concerned with automated vehicles. Since people might be automated vehicle customers and buyers, it is crucial for the sustainability of these emerging forms of personal transportation to consider when and where confidentiality and autonomous driving will communicate. Whenever an entity is associated with such an autonomous car, the interests of privacy appear relevant [14]. Internet-of-things feature enables Telco's, such as private insurers, to collect large quantities of data about car users that are vulnerable to privacy. If a small financial reward is given, however, individuals are willing to sacrifice their privacy towards car insurers. Users consider behavioural privacy more important than local and spatial privacy [15]. The vehicle has become a powerful sensor network within the Autonomous Vehicle System, absorbing data from the world, from several other vehicles (as well as from the car owner) including feeding that to other vehicles and facilities to support in smooth operation, environment protection, and road traffic. The Automobile Grid is another Internet of Things (IoT), that we refer to as the Internet of Vehicles (IOV), which is capable of making its very own choices about driving people to their targets $[16,17]$. The core idea of an Internet of Things (IoT) is always to equip computation, processing, and network control with physical objects to allow socialisation amongst them. The Internet of Vehicles (IoV) is indeed an IoT affiliate that has made substantial strides using networking technologies. Vehicles linked through the Web are able to exchange information which can greatly increase the efficiency of traffic congestion [18]. A Social Internet of Vehicle becomes the automobile application which has transformed the current Intelligent Transportation System (ITS) and Vehicle Call Services into the next level of Intelligent by incorporating socialising and constant communication aspects. Furthermore, as information is collected as well as processed at various layers of all its infrastructure, the task of privacy management appears important [19].

The present research study tries to explore the concern of information privacy for the Internet of the vehicle (CFIOVIP). The study intends to explore a causal link between concern for the Internet of vehicle information privacy and behaviour intentions for the transportation community.

\section{Literature Review}

2.1. Present Measurement Instruments for the Concern of Information Privacy. The concern for information privacy was first measured by Smith, Milberg, and Burke [20] using four-dimensional factors: improper access, unauthorised secondary usage, errors, and collection. The measurement and validation of four dimensions of concern for information privacy were confirmed based on first-order constructs. Later, a research study conducted by Stewart and Segars [21] confirmed and validated the concern for information privacy model as developed by [20]. However, in response to the firstorder model developed by Smith et al. [20], the study conducted by Stewart and Segars [21] tested and validated their research based on a model with more complex dimensions 
with second-order constructs. Similarly, a research study as carried by Malhotra, Kim, and Agarwal [22] tested and confirmed a first-order model for the information privacy for Internet users with three dimensions, namely, awareness, control and collection. In contrast, a study that was examined by Rose [23] as the cross-country regulatory comparison for the concern for information privacy indicated some differences for US and non-US data. The comparison validated one-factor information privacy concern model for US data while second-order information privacy concern was confirmed for non-US data. Similarly, a research thesis as investigated by Yau [24] revealed a significant difference between different groups of respondents for the concern for information privacy in the case of New Zealand research. The study concluded that upper level of respondents is more concerned with information privacy rather than lower-level respondents in terms of social status. In contrast, a study was conducted by Bélanger and Crossler [25] on the four dimensional model of concern for information privacy at individual, organizational, and societal levels with different order constructs. At individual level, the first-order model was validated, while on organizational and societal levels, the second-order model was confirmed and validated for the concerns of information privacy using the student-based data in the US environment.

Different studies also considered the limitation and usage of measurement and scale development of concern for information privacy in a different context, like the study of $[26,27]$. The study concluded with the limited use of information privacy concern's scale development with differences in dimensions for non-US studies and concluded with an argument that a single model and order is not viable for different context and nations. However, scale and dimension can be validated differently as per the requirements of the studies. Likewise, the study conducted by Lee, Chung, Han, and Song [28] considered the scale development and measurement of concern for information privacy in a medical context. They confirmed a $2^{\text {nd }}$ order model for the concerns for information privacy in medical context based on three dimensions namely; errors, collections, and secondary usage and access. The study conducted by Osatuyi [8] considered the context of social media for testing the basic model of information privacy concern. The study confirmed the second-order construct based on the dimensions of errors, collection, secondary usage, and unauthorised access. Similarly, another piece of research study concluded with four dimensional $2^{\text {nd }}$ order construct for the concern of information privacy with the dimensions like unauthorised access, secondary usage, collection, and personal information providing concerns $[29,30]$. However, in response to the high expectations of South African citizen for online information privacy concern, it was not practical to ensure due to variation in regulatory requirement of the country to apply completely the second-order model for non-US data [31]. The study tested the model based on eleven different principles of online information privacy as opposed to the basic privacy of information concern as developed by [20].
2.2. Concern for the Internet of Vehicle Information Privacy (CFIOVIP). The concept of the Internet of the vehicle and its related issue of privacy concern found its origin from the study of Horswill and Coster [32], where the researcher aimed to analyse the impact of age, mileage, and gender of vehicle driver with car usual and expected performance. They argued that if the vehicles are connected through a servicer like the Internet of vehicle, there are more chances of avoiding the risk associated with car driving. However, they did not use any proxy for estimating the Internet of a vehicle for their research, rather they suggested for its inclusion in future research. Similarly, another piece of research as conducted by Puri [33] considered a satellite-based technology named as "unmanned Arial vehicle," as the introductory application of Internet of vehicle concept in the transport industry for monitoring all types of vehicle and transports on the roads. However, a research study as examined by Barón and Green [34] considered some detailed measure for the performance of driving based on manual as well as speech to analyse their effect on the task performance of the vehicle.

A more detailed and comprehensive measure of the Internet of the vehicle was originated from the study of [35]. They considered the IOV for the transport context with four different dimensions, namely, general information of the vehicle, safety information of the vehicle, motion control of individuals, and motion control of a group [36]. Similarly, a study conducted by Händel, Ohlsson, Ohlsson, Skog, and Nygren [37] suggested to include the smart-phone technology to automate the vehicle for traffic monitoring as well as for insurance purpose usage to measure the Internet of the vehicle concept. In contrast, some of the research studies considered knowledge management as the proxy for measuring the IOV to enhance the intelligent parking system [38]. More dynamic research for measuring the IOV through modern multidimensional categories includes an ad-hoc network of vehicles, smartphone networks, intervehicle network, intravehicle network, and network with beyond vehicle [39]. In contrast, a study as investigated by $\mathrm{Ni}$ et al. [40] argued about the measurement of the Internet of the vehicle under the dimensions of driver-assisted to automatic vehicles. Finally, a block-chain based system of the Internet of the vehicle can be more efficient in terms of information privacy concern for the transport context [41]. However, the block-chain technology has some loopholes with respect to the application with the Internet of the vehicle for considering the information privacy concern.

The below model in Figure 1 is based on the present research for testing the transport anxiety using the Internet of vehicle concept by considering the concern for information privacy for transport context and its ultimate impact on the behavioural intentions of the ultimate users or driver of vehicles in the transport sector.

\section{Methodology}

3.1. Development of Scale. The present exploratory research investigation is aimed to explore the transport anxiety using the Internet of vehicle by considering the concern for 


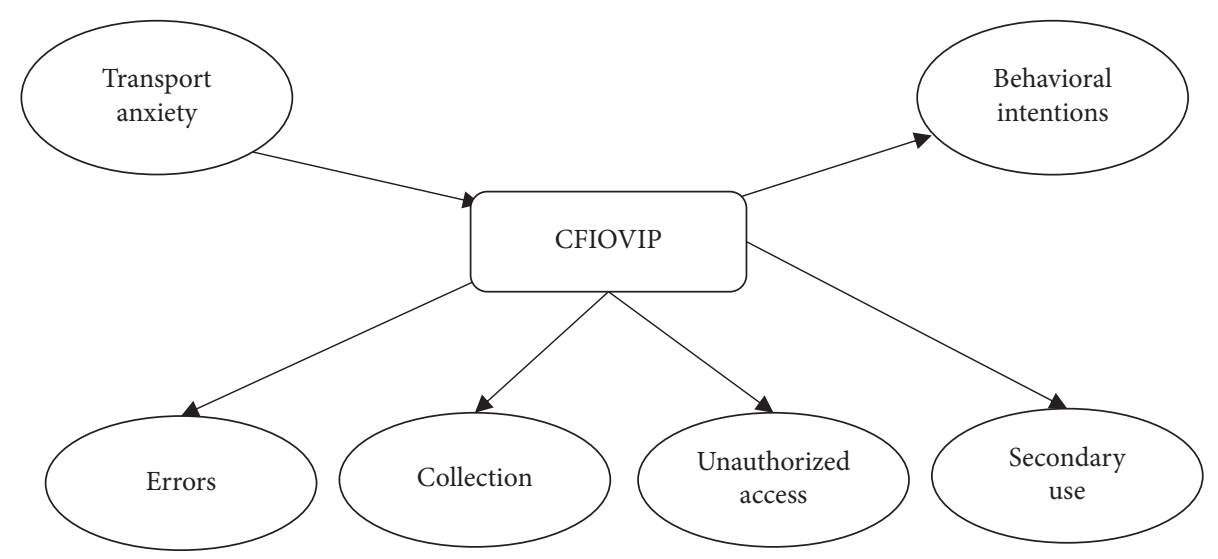

Figure 1: Conceptual framework for the CFIOVIP model.

information privacy and its ultimate impact on the behaviour intentions for the ultimate user or drivers of connected vehicles in the transport sector [42]. For this purpose, a survey-based questionnaire research instrument was developed as per the measurement and scales adopted by $[8,20,21,28]$. These include the constructs like concerns of information privacy with all their four dimensions, namely, errors, collection, unauthorised access, and secondary usage along-with the other construct like behaviour intentions of users (Appendix A). The constructs measuring the concerns for information privacy for the Internet of the vehicle are measured on multiple item bases on a scaled from strongly disagree-strongly agree with five-point Likert values linear scale. Similarly, the measure for transport anxiety for the Internet of the vehicle (Appendix B) was adopted as the measurement and scale adopted from the studies of $[35,39,43]$. It was also measured on multiple item bases on a scaled from strongly disagree-strongly agree five-point Likert values linear scale [44]. However, the behaviour intention was measured on a linear scale of three points from highly likely to not likely.

The first versions of survey questionnaire research instrument of this study were verified and approved from the expert and authorised persons from the transport sector as well as from the field of information privacy to validate the constructs and their relevant items related to the Internet of vehicle, concerns of information privacy, behavioural intentions, etc. Additionally, the remaining responses for the validity and reliability of item statement related to each dimension of the constructs were received from the student's community at undergraduate and graduate level for the clarity of question statements which helped towards the formation of the final version of the questionnaire.

3.2. Design of the Survey. The present study used an online type of questionnaire survey for the collection of data related to the dimensions and constructs including their item statements. For this purpose, the questionnaire was shared through the personal e-mail address, including the social media sites of students studying the course of an information system at undergraduate and graduate level in different universities and using an automated and connected vehicle for the application of concept for the Internet of vehicle. Any data related to the personal information of the respondents were not demanded to maintain the privacy of the respondents as per the regulations of IRB (the data of surveybased questionnaire used to support the findings of this study are available from the corresponding author upon request). A total number of 425 online questionnaires were shared to targeted respondents but only 357 responses were received dully filled with all the required information with a rate of response of $84 \%$. The demographic characteristics include age, gender, and Internet of vehicle (IOV) users.

\section{Analysis of Data and Discussion on Results}

The present exploratory study meant to analyse the validity and identification of structure for concern for the Internet of vehicle information privacy (CFIOVIP) and the evaluation of its nomological network. The process was executed on two phases: validation and identification of the structure based on the factors of CFIOVIP and evaluation of the model based on CFIOVIP's nomological network.

4.1. First Step: Factor Structure Identification of CFIOVIP. The first step of analysis includes the identification and validation of factor structures, scales, and measurements for the concern for the Internet of vehicle information privacy (CFIOVIP) as per the requirements of the study and based on previous historical studies of $[22,45,46]$. For achieving this objective, the study executed at first the analysis of confirmatory factors and secondly exploratory analysis of factors was done for the various items statements related to the factors of CFIOVIP.

For the estimation of factor analysis using exploratory characteristics, SPSS software of IBM was utilized. Using the EFA feature of SPSS, the technique of principal component analysis with the help of VARIMAX rotation option as well as the normalization of Kaiser was executed. For this purpose, CFIOVIP was initially estimated with 4 adapted dimensions as used by $[45,46]$. Table 1 indicates that 3 components were explored using this function with clean item loading and having no cross-loading at all. The dimensions like secondary usage and unauthorised access 
TABLE 1: PCA using VARIMAX rotation.

\begin{tabular}{lccccc}
\hline \multirow{2}{*}{ Constructs } & Items & \multicolumn{4}{c}{ Component } \\
& & 1 & 2 & 3 & CA \\
\hline \multirow{5}{*}{ Collection } & C1 & & 0.803 & & \\
& C2 & & 0.877 & & 0.861 \\
& C3 & & 0.855 & & \\
Error & C4 & & 0.826 & & \\
& E1 & & & 0.832 & \\
& E2 & & & 0.814 & 0.764 \\
Secondary usage & E3 & & & 0.825 & \\
& SU1 & 0.802 & & & \\
& SU2 & 0.771 & & & \\
& SU3 & 0.770 & & & \\
Unauthorised access & SU4 & 0.768 & & & \\
& UAA1 & 0.771 & & & \\
& UAA2 & 0.862 & & & 0.929 \\
& UAA3 & 0.818 & & & \\
& UAA4 & 0.841 & & & \\
Rotation SS loadings & UAA5 & 0.786 & & & \\
& Total & 4.225 & 2.202 & 2.354 & \\
& \% age & 34.585 & 24.456 & 20.196 & \\
& Cumulative & 34.585 & 59.041 & 79.237 & \\
\hline
\end{tabular}

indicated the same component's factors as used in the previous historical literature stated above.

The factor's reliability was estimated using the process of exploratory factor analysis as suggested by [47]. The reliability as shown from the estimated figures of Cronbach Alpha for the factors finalized for exploratory factor analysis process is above the minimum acceptable limit of 0.70 as suggested by [48]. As, secondary usage and unauthorised access, their factors were also combined in the same column to reflect the factors for a single construct as shown in Table 2.

The confirmatory factor analysis process is used evaluate the effectiveness of the structure of the proposed model of CFIOVIP containing 16 items to measure the relevant constructs as per the similar estimation scales and measurements used by $[45,46]$. The present research has executed the procedure of confirmatory factor analysis process based on covariance matrices as originally adopted by [45]. As per the study examined by Osatuyi [45], the confirmatory factor analysis process enable the scholars to respecify, estimate, and originally specify univariate and multivariate model based on related dependencies and relationships and also enable the researchers to estimate the previously unobserved constructs. Table 3 depicts the model construction fit for factors structures based on $1^{\text {st }}$ order and $2^{\text {nd }}$ order constructs for CFIOVIP. The models 1, 2, and 3 indicate the factor construction based on $1^{\text {st }}$ order constructs for concern for the Internet of vehicle information privacy. Models 4 and 5 indicate the factor construction based on $2^{\text {nd }}$ order constructs for CFIOVIP.

As per the table estimates, the first model indicates the first-order construction of CFIOVIP based on 16 items based on 4 dimensions, namely, collection, error, secondary usage, and unauthorised access. The first model is based on par the construct study for a similar domain for the unidimensional factors by [46]. If the study accepts this model,
TABLE 2: PCA using VARIMAX rotation.

\begin{tabular}{lccccc}
\hline \multirow{2}{*}{ Constructs } & Items & \multicolumn{4}{c}{ Component } \\
& & 1 & 2 & 3 & CA \\
\hline \multirow{5}{*}{ Collection } & C1 & & 0.803 & & \\
& C2 & & 0.877 & & 0.861 \\
& C3 & & 0.855 & & \\
& C4 & & 0.826 & & \\
& E1 & & & 0.832 & \\
Error & E2 & & & 0.814 & 0.764 \\
& E3 & & & 0.825 & \\
& UAA1 & 0.771 & & & \\
& UAA2 & 0.862 & & & \\
& UAA3 & 0.818 & & & \\
Information access & UAA4 & 0.841 & & & \\
& UAA5 & 0.786 & & & \\
& UAA6 & 0.802 & & & 0.929 \\
& UAA7 & 0.771 & & & \\
& UAA8 & 0.770 & & & \\
Rotation SS loadings & UAA9 & 0.768 & & & \\
& Total & 4.225 & 2.202 & 2.354 & \\
& \% age & 34.585 & 24.456 & 20.196 & \\
& Cumulative & 34.585 & 59.041 & 79.237 & \\
\hline
\end{tabular}

it can be inferred that the CFIOVIP can be measured as one single construct based on 16 item statements from the proposed research.

The table also indicates that the second model comprises of the 16 item statements for CFIOVIP is comprised of two main dimensions of the study. One dimension is the combination of collection and error constructs while the other is comprised of secondary usage and unauthorised access to information. It is also consistent with studies of $[22,45]$.

Table 3 also indicates the third model based on three constructs: collection, error, and unauthorised access + secondary usage collectively measures the concern for the Internet of vehicle information privacy by considering all the 16 item statement as equally important for the measurement and estimations. This model was also similar to that from the study of [45].

The table also indicates the $2^{\text {nd }}$ order construct for the variable concern for the Internet of vehicle information privacy (CFIOVIP) based on three-dimensional factors, namely, collection, error, and unauthorised access + secondary usage. The RMSEA value for this model is as low as 0.001 which increases the validity and acceptability of $4^{\text {th }}$ model $2^{\text {nd }}$ order construct of CFIOVIP and is also consistent with the similar results from [45].

The table also indicates the $5^{\text {th }}$ model $2^{\text {nd }}$ order construction of CFIOVIP based on four dimensions like collection, error, secondary usage, and unauthorised access. This model was established to compare it with the $4^{\text {th }}$ model. However, its RMSEA value is slightly higher than the $4^{\text {th }}$ model which decreases the validation of the fifth model as compared to the $4^{\text {th }}$. These results also verify the similar findings from the study of [45]. The fit indices of the model indicate that $1^{\text {st }}$ and $2^{\text {nd }}$ models are not acceptable based on the values from NFI, GFI, AGFI, CFI, and RMSEA. However, models 3,4 , and 5 are acceptable based on the criteria 
TABLE 3: Model fit measures CFA for alternate factor structure.

\begin{tabular}{|c|c|c|c|c|c|c|}
\hline \multirow[b]{2}{*}{ Model fit indices } & \multirow[b]{2}{*}{ Standard indices } & \multicolumn{5}{|c|}{ Alternative CFIOVIP structure } \\
\hline & & $\begin{array}{l}\text { Model } 1 \\
1^{\text {st }} \text { order }\end{array}$ & $\begin{array}{l}\text { Model } 2 \\
1^{\text {st }} \text { order }\end{array}$ & $\begin{array}{l}\text { Model } 3 \\
1^{\text {st }} \text { order }\end{array}$ & $\begin{array}{l}\text { Model } 4 \\
2^{\text {nd }} \text { order }\end{array}$ & $\begin{array}{l}\text { Model } 5 \\
2^{\text {nd }} \text { order }\end{array}$ \\
\hline Chi-square $\left(\chi^{2}\right)$ & & $795.3^{*}$ & $656.1^{*}$ & $267.5^{*}$ & 121.9 & 211.7 \\
\hline Degree of freedom (df) & & 124 & 123 & 129 & 124 & 171 \\
\hline Chi-square/degree of freedom $\left(\chi^{2} / \mathrm{df}\right)$ & Must be $\leq 3.00$ & 6.41 & 5.33 & 2.07 & 0.98 & 1.24 \\
\hline Normed fit index (NFI) & Must be $\geq 0.90$ & 0.83 & 0.93 & 0.96 & 0.99 & 0.98 \\
\hline The goodness of fit index (GFI) & Must be $\geq 0.90$ & 0.79 & 0.87 & 0.93 & 0.97 & 0.91 \\
\hline Adjusted goodness of fit index (AGFI) & Must be $\geq 0.80$ & 0.71 & 0.77 & 0.92 & 0.99 & 0.99 \\
\hline Comparative fit index (CFI) & Must be $\geq 0.90$ & 0.86 & 0.91 & 0.96 & 0.99 & 0.99 \\
\hline Root mean square error of approximation (RMSEA) & Must be $\leq 0.06$ & 0.17 & 0.15 & 0.04 & 0.00 & 0.02 \\
\hline
\end{tabular}

TABle 4: Models 4 and 5 convergent validity.

\begin{tabular}{|c|c|c|c|c|c|c|c|c|c|}
\hline \multirow[b]{2}{*}{ Final constructs } & \multirow[b]{2}{*}{ Items } & \multicolumn{4}{|c|}{ Model 4} & \multicolumn{4}{|c|}{ Model 5} \\
\hline & & $\begin{array}{c}\text { Standardized } \\
\text { loadings }\end{array}$ & $\begin{array}{c}\mathrm{t}- \\
\text { statistic }\end{array}$ & AVE & $\mathrm{CR}$ & $\begin{array}{c}\text { Standardized } \\
\text { loadings }\end{array}$ & $\begin{array}{c}\mathrm{t}- \\
\text { statistic }\end{array}$ & AVE & CR \\
\hline \multirow{4}{*}{ Collection } & $\mathrm{C} 1$ & 0.964 & 2.38 & 0.72 & 0.95 & 0.816 & 2.17 & \multirow{4}{*}{0.71} & \multirow{4}{*}{0.91} \\
\hline & $\mathrm{C} 2$ & 0.955 & 5.81 & & & 0.877 & 2.70 & & \\
\hline & $\mathrm{C} 3$ & 0.974 & 5.20 & & & 0.847 & 2.28 & & \\
\hline & $\mathrm{C} 4$ & 0.868 & 5.07 & & & 0.821 & 4.04 & & \\
\hline \multirow{3}{*}{ Error } & E1 & 0.814 & 6.90 & 0.60 & 0.88 & 0.810 & 8.05 & \multirow{3}{*}{0.68} & \multirow{3}{*}{0.86} \\
\hline & $\mathrm{E} 2$ & 0.833 & 6.48 & & & 0.819 & 6.16 & & \\
\hline & E3 & 0.878 & 7.93 & & & 0.843 & 8.02 & & \\
\hline \multirow{9}{*}{$\begin{array}{l}\text { Information access = secondary } \\
\text { usage + unauthorised access }\end{array}$} & IA1 & 0.845 & 11.05 & 0.59 & 0.96 & 0.809 & 12.19 & \multirow{9}{*}{0.639} & \multirow{9}{*}{0.941} \\
\hline & IA 2 & 0.847 & 12.60 & & & 0.771 & 9.99 & & \\
\hline & IA3 & 0.806 & 13.81 & & & 0.771 & 12.07 & & \\
\hline & IA 4 & 0.822 & 15.91 & & & 0.771 & 12.00 & & \\
\hline & IA5 & 0.793 & 11.96 & & & 0.765 & 10.82 & & \\
\hline & IA6 & 0.903 & 11.51 & & & 0.859 & 10.17 & & \\
\hline & IA7 & 0.953 & 11.76 & & & 0.814 & 16.35 & & \\
\hline & IA 8 & 0.892 & 15.45 & & & 0.834 & 13.03 & & \\
\hline & IA9 & 0.875 & 10.90 & & & 0.794 & 9.66 & & \\
\hline
\end{tabular}

defined. Model 4 indicates superior acceptability and validity based on the lowest RMSEA value of 0.001 .

Table 4 indicates the standardized factor loadings, $t$ values, average variance extracted, and composite reliability which indicate the convergent validity of the constructs. For a construct to be valid and reliable based on factor loading, its standardized values along-with composite reliability should exceed the minimum criteria of 0.70 and its average variance extracted should be greater than 0.50 , while the $t$ values should be greater than 1.96 for significance as per the suggestions of [47-49]. The estimated results indicated in the table infer that all the constructs measuring the CFIOVIP are reliable and valid for the study which indicates the convergent validity based on strength properties of the constructs.

The item statement and relevant constructs measuring the CFIOVIP indicates strong properties for $4^{\text {th }}$ and $5^{\text {th }}$ model. However, the $4^{\text {th }}$ model's properties indicate better estimates as compared to model 5 .

The discriminant validity for construct measuring CFIOVIP is displayed in Table 5 which indicates the correlation's coefficient between the constructs like collection, error, and information access (secondary usage + unauthorised access). As per the suggestion of Fornell
TABLE 5: Associations (correlation) between latent variables.

\begin{tabular}{lccc}
\hline & IA & C & E \\
\hline Information access (IA) & 0.80 & & \\
Collection (C) & 0.77 & 0.84 & \\
Error (E) & 0.70 & 0.764 & 0.82 \\
\hline
\end{tabular}

and Larcker [49], for the constructs to discriminately valid, the correlation coefficient's value between them should be less than the average variance extracted square root of each construct. The estimated figures of the table indicate that all the constructs, namely, collection, error, and information access, are valid and reliable according to the criteria of discernment validity.

4.2. Second Step: Validation of CFIOVIP. The present study was aimed to test the validity of CFIOVIP construct based on nomological measures as suggested by [45]. The nomological approach requires a $2^{\text {nd }}$ order construct to be inserted between an input/explanatory variable and an outcome variable as per [45]. For achieving this objective, the $2^{\text {nd }}$ order 
TABle 6: Model fit measures for CFIOVIP.

\begin{tabular}{|c|c|c|c|}
\hline Model fit indices & Standard indices & Model $62^{\text {nd }}$ order & Model $72^{\text {nd }}$ order \\
\hline Chi-square $\left(\chi^{2}\right)$ & & 912.75 & 741.72 \\
\hline Degree of freedom $(\mathrm{df})$ & & 178 & 203 \\
\hline Chi-square/degree of freedom $\left(\chi^{2} / \mathrm{df}\right)$ & Must be $\leq 3.00$ & 5.13 & 3.65 \\
\hline Normed fit index (NFI) & Must be $\geq 0.90$ & 0.97 & 0.95 \\
\hline The goodness of fit index (GFI) & Must be $\geq 0.90$ & 0.94 & 0.92 \\
\hline Adjusted goodness of fit index (AGFI) & Must be $\geq 0.80$ & 0.98 & 0.97 \\
\hline Comparative fit index (CFI) & Must be $\geq 0.90$ & 0.98 & 0.97 \\
\hline Root mean square error of approximation (RMSEA) & Must be $\leq 0.06$ & 0.03 & 0.05 \\
\hline
\end{tabular}

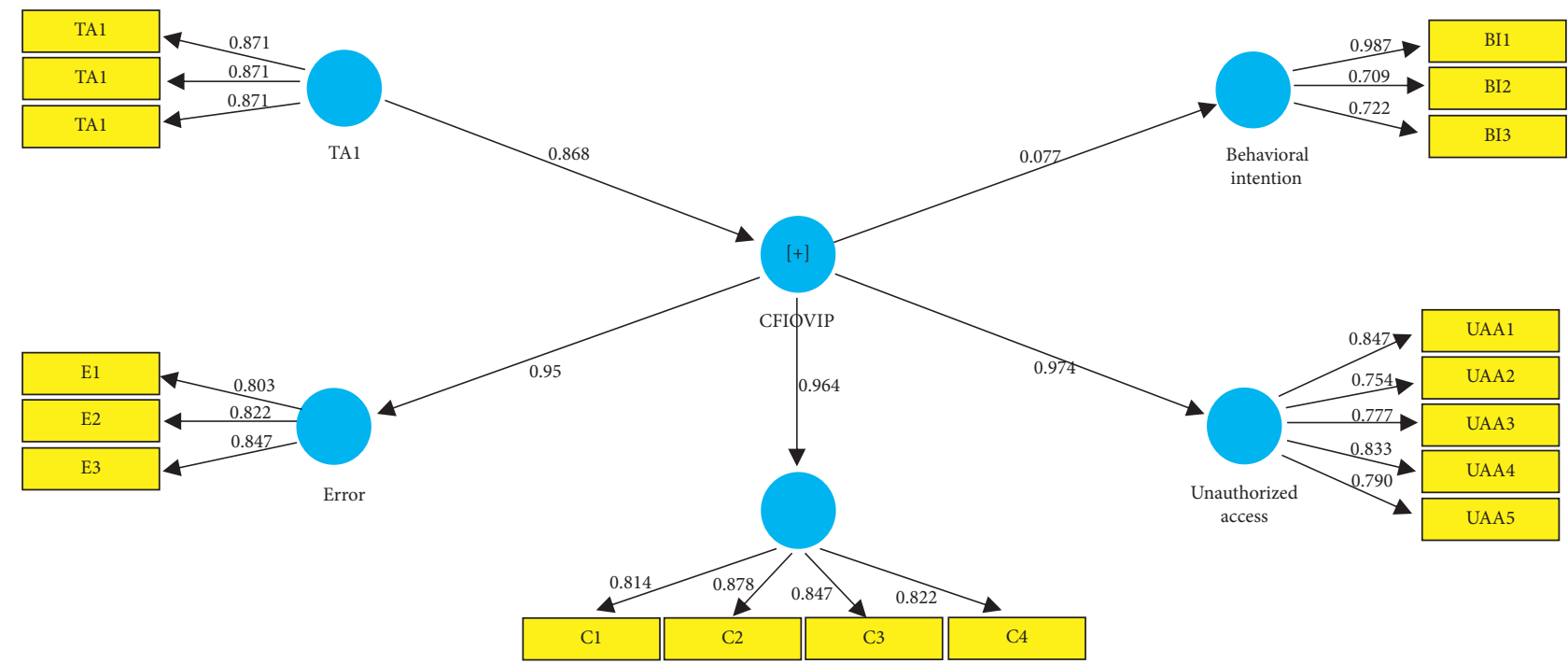

Figure 2: Structure model of CFIOVIP (using smart PLS).

construct based on $4^{\text {th }}$ model of CFIOVIP was placed between the construct of transport anxiety and the behavioural intentions of transport users within the framework of the Internet of vehicle context. Table 6 reports the $2^{\text {nd }}$ order structural model based on models 6 and 7 based on 3 dimensions (collection, error, and information access) and 4 dimensions (collection, error, secondary usage, and unauthorised access), respectively.

Table 6 reports the structural model goodness of fit indices in the form of NFI, GFI, AGFI, CFI, and RMSEA. The indices indicate that model 6 based on the 3-dimension structure for measuring CFIOVIP is stronger as compared to model 7.

The structure model based on models 4 and 6 is depicted in Figure 2 indicates the mediating relationship of CFIOVIP between transport anxiety and behaviour intentions of the users of the Internet of vehicle.

Figure 2 above indicates a good fit and relevant loading values as per standardized threshold level for factor loading indicating a strong and positive relationship between the constructs like transport anxiety and behaviour intensions of IOV users which is strongly and positively mediated by CFIOVIP.

\section{Conclusions}

The present exploratory research study was mean to test the validity and measurement of concern for information privacy in transport context with the application of Internet of vehicle by applying and replicating the previous research studies basis like $[22,45,46]$. The previous study mainly considered the social media context for information privacy concern. The present research study tries to test the personal information concern in case of the Internet of vehicle context which may be a bigger issue in today's world of the connected vehicle. The information privacy domain requires a large set of different context to test their validity based on the existing model for different industries that requires the concern of information privacy for their users.

For this purpose, a survey-based online questionnaire was developed by carefully examining the item statements of previous research studies and adjusting those item statements based on the requirement of the present study by considering Internet of vehicle context for the constructs like transport anxiety, concern for information privacy, and behaviour intentions of the users. For this purpose, the exploratory and confirmatory analysis processes were performed for testing the validity of concern for the Internet of vehicle information privacy. A total number of 357 responses were received online which were complete in all respects from college and university students studying information system course at undergraduate and graduate levels. 
The estimated results obtained from exploratory and confirmatory factor analysis revealed that 3-dimension construct containing collection, error, and information accuracy measuring concern for the Internet of vehicle information privacy (CFIOVIP) was validated through second-order construction with strong goodness of fit estimates. The relevant factors were reliable and valid as per their internal and external validity estimates of Cronbach Alpha, average variance extracted, composite reliability, discriminant validity, and factor loading values including their fitness indices for 16 items for 3-dimension construct of CFIOVIP. The factor loading values for all the 16-items for 3-dimensions like collecting, error, and information access were exceeding the minimum standard limit of 0.70 . The Cronbach Alpha and composite reliability values for the same set of dimensions revealed the values exceeding the minimum required level of 0.70 . Additionally, the average variance extracted was also exceeding the standardized minimum limit of 0.50. Similarly, the discriminant validity of the construct was also confirmed by having the values of coefficients of correlation for collection, error, and information accuracy less than the average variance extracted square root value. Finally, the model fit indices as indicated by NFI, GFI, AGFI, NFI, and RMSEA were also good and indicating stronger properties, especially for 2 nd order construct of CFIOVIP, construct based on 3 -dimension $4^{\text {th }}$ model as well as in case of $6^{\text {th }}$ model based on the same 3 -dimension, and 2 nd order construct for CFIOVIP using the structural equation modelling method.

The study further revealed a strong and optimistic link between transport anxiety and behavioural intentions for the use of the Internet of the vehicle as mediated strongly and positively by CFIOVIP. The $t$ values were significant for the relationship between transport anxiety, concern for the Internet of vehicle information privacy, and behavioural intentions of the users of connected vehicles. The findings of the study indicate that Internet of vehicle users view secondary usage of information and unauthorised access of information as the same dimension with the title of information access for measuring CFIOVIP along with two other constructs like collection and error in information for the Internet of vehicle context. The study recommends a $2^{\text {nd }}$ order CFIOVIP construct based on three dimensions, namely, collection, error, and information access for testing the present domain of the study. The future research may, however, be applied to other domain using the same set of a statement with an amendment for items as per the desired context of the study.

\section{Appendix}

\section{A. Four dimension of concern for information privacy for IOV.}

(1) Error (E)

(i) Internet of vehicle (IOV) system should be capable enough to ensure the accuracy of personal information stored in their database. (ii) Internet of vehicle (IOV) system should be capable enough to have an efficient procedure for the correction of personal information errors.

(iii) Internet of vehicle (IOV) system should be able to allocate extra time for the purpose of verification of personal information accuracy in their storage database before recommending it for usage.

(2) Collection (C)

(i) I am not convenient of sharing personal information through any of the feature linked with Internet of vehicle.

(ii) I am not convenient in sharing the information related to my present location through any of the feature linked with Internet of vehicle.

(iii) It is not convenient for me to share my personal information in Internet of vehicle through any vehicle where I am registered.

(iv) I have a greater concern about Internet of vehicle gathering so much personal information about me.

(3) Unauthorised Access (UAA)

(i) There should be a protection from an unauthorised access of computer databases that contain my personal information without considering any involved costs.

(ii) The Internet of vehicle system should be capable enough to deny the access of unauthorised person who are trying to access my personal information.

(iii) There should be a secured location for the storage of databases containing personal information.

(iv) There should be a restriction for a user to access other user's personal information illegally at the system of Internet of vehicle.

(4) Secondary Usage (SU)

(i) The authorities controlling the system of Internet of vehicle should not utilize the data related to the personal information without the prior approval and authorization of relevant individual.

(ii) The authorities controlling the system of Internet of vehicle should be bound to use the personal information provided by any individual for the purpose it was provided.

(iii) The authorities controlling the system of Internet of vehicle should not provide the personal information of any individual to any third party without prior approval and authorization of the relevant individual.

(5) Behavioural Intention (BI)

At what level of likely/not likely you are, for the upcoming 3 years to the following: 
(i) Giving your personal information for the Internet of vehicle system.

(ii) Making your personal account at Internet of vehicle system for the other individuals searching you easily.

(iii) Sharing your personal information on the system of Internet of vehicle for your friends to find you?

B. Concern for information privacy for internet of vehicle context (CFIOVIP) measurement scales.

Transport Anxiety (TA)

(1) It makes me frustrated sometimes for enhancing the usage Internet of vehicle (IOV) system.

(2) It makes me afraid sometimes of deleting my pictures/important messages/personal information stored in the database of Internet of vehicle (IOV) system.

(3) It makes me afraid of sending mistakenly my personal information to the personal who is not actually the recipient on the system of Internet of vehicle (IOV) system.

\section{Data Availability}

The data of survey-based questionnaire used to support the findings of this study are available from the corresponding author upon request. Any data related to the personal information of the respondents were not demanded to maintain the privacy of the respondents as per the regulations of IRB.

\section{Conflicts of Interest}

The authors declare no conflicts of interest.

\section{Acknowledgments}

The authors gratefully acknowledge the financial grant (600IRMI/FRGS 5/3 (262/2019)) given by Ministry of Education Malaysia and Accounting Research Institute, HiCOE, Universiti Teknologi MARA, for all supports and resources. Furthermore, special thanks to Fundamental Research Grant Scheme (FRGS) Vot No. FRGS/1/2019/SS09/TAYLOR/01/1 sponsored by Malaysian Ministry of Higher Education.

\section{References}

[1] F. Yang, S. Wang, J. Li, Z. Liu, and Q. Sun, "An overview of internet of vehicles," China Communications, vol. 11, no. 10, pp. 1-15, 2014.

[2] F. Sufian and F. Kamarudin, "The impact of ownership structure on bank productivity and efficiency: evidence from semi-parametric malmquist productivity index," Cogent Economics and Finance, vol. 2, no. 1, pp. 1-27, 2014.

[3] O. Alaeddin, R. Altounjy, Z. Zainudin, and F. Kamarudin, "From physical to digital: investigating consumer behaviour of switching to mobile wallet," Polish Journal of Management Studies, vol. 17, no. 2, pp. 18-30, 2018.
[4] D. Singh and M. Singh, "Internet of vehicles for smart and safe driving," in Proceedings of the Paper presented at the 2015 international conference on connected vehicles and expo (ICCVE), Shenzhen, China, October 2015.

[5] M. N. O. Sadiku, M. Tembely, and S. M. Musa, "Internet of vehicles: an introduction," International Journal of Advanced Research in Computer Science and Software Engineering, vol. 8, no. 1, p. 11, 2018.

[6] M. Priyan and G. U. Devi, "A survey on internet of vehicles: applications, technologies, challenges and opportunities," International Journal of Advanced Intelligence Paradigms, vol. 12, no. 1-2, pp. 98-119, 2019.

[7] X. Shen, R. Fantacci, and S. Chen, "Internet of vehicles [scanning the issue]," Proceedings of the IEEE, vol. 108, no. 2, pp. $242-245,2020$.

[8] B. Osatuyi, "Empirical examination of information privacy concerns instrument in the social media context," AIS Trans. Replication Res.vol. 1, p. 3, 2015b.

[9] Z. D. Ozdemir, J. H. Benamati, and H. J. Smith, "A crosscultural comparison of information privacy concerns in Singapore, Sweden and the United States," in Proceedings of the Paper presented at the Proceedings of the 18th Annual International Conference on Electronic Commerce: e-Commerce in Smart Connected World, Suwon, South Korea, August 2016.

[10] L. Baruh, E. Secinti, and Z. Cemalcilar, "Online privacy concerns and privacy management: a meta-analytical review," Journal of Communication, vol. 67, no. 1, pp. 26-53, 2017.

[11] C. Lutz, C. P. Hoffmann, E. Bucher, and C. Fieseler, "The role of privacy concerns in the sharing economy," Information, Communication \& Society, vol. 21, no. 10, pp. 1472-1492, 2018.

[12] H. I. Hussain, A. R. A. Hadi, A. Mohamed-Isa, M. A. Salem, F. Kamarudin, and N. H. Jabarullah, "Adjustment to target debt maturity and equity mispricing: evidence from Asia pacific," Polish Journal of Management Studies, vol. 17, no. 2, pp. 87-100, 2018a.

[13] P. F. Wu, J. Vitak, and M. T. Zimmer, “A contextual approach to information privacy research," Journal of the Association for Information Science and Technology, vol. 71, no. 4, pp. 485490, 2020.

[14] D. J. Glancy, "Privacy in autonomous vehicles," Santa Clara Law Review, vol. 52, pp. 1171-1239, 2012.

[15] S. Derikx, M. De Reuver, and M. Kroesen, "Can privacy concerns for insurance of connected cars be compensated?" Electronic Markets, vol. 26, no. 1, pp. 73-81, 2016.

[16] J. Joy and M. Gerla, "Internet of vehicles and autonomous connected car-privacy and security issues," in Proceedings of the 2017 26th International Conference on Computer Communication and Networks (ICCCN), Vancouver, Canada, JulyAugust 2017.

[17] H. I. Hussain, I. S. Z. Abidin, A. Ali, and F. Kamarudin, "Debt maturity and family related directors: evidence from A developing market," Polish Journal of Management Studies, vol. 18 , no. 2, pp. 118-134, 2018b.

[18] R. Silva and R. Iqbal, "Ethical implications of social internet of vehicles systems," IEEE Internet of Things Journal, vol. 6, no. 1, pp. 517-531, 2019.

[19] T. A. Butt, R. Iqbal, K. Salah, M. Aloqaily, and Y. Jararweh, "Privacy management in social internet of vehicles: review, challenges and blockchain based solutions," IEEE Access, vol. 7, pp. 79694-79713, 2019.

[20] H. J. Smith, S. J. Milberg, and S. J. Burke, "Information privacy: measuring individuals' concerns about 
organizational practices," MIS Quarterly, vol. 20, no. 2, pp. 167-196, 1996a.

[21] K. A. Stewart and A. H. Segars, "An empirical examination of the concern for information privacy instrument," Information Systems Research, vol. 13, no. 1, pp. 36-49, 2002.

[22] N. K. Malhotra, S. S. Kim, and J. Agarwal, "Internet users' information privacy concerns (IUIPC): the construct, the scale, and a causal model," Information Systems Research, vol. 15, no. 4, pp. 336-355, 2004.

[23] E. A. Rose, "An examination of the concern for information privacy in the New Zealand regulatory context," Information \& Management, vol. 43, no. 3, pp. 322-335, 2006.

[24] A. Yau, "Measuring levels of privacy concern: context and trade-offs between competing desires," Victoria University of Wellington, School of Information Management, Wellington, New Zealand, Master of Information Management, 2007.

[25] F. Bélanger and R. E. Crossler, "Privacy in the digital age: a review of information privacy research in information systems," MIS Quarterly, vol. 35, no. 4, pp. 1017-1041, 2011.

[26] S. Preibusch, "Guide to measuring privacy concern: review of survey and observational instruments," International Journal of Human-Computer Studies, vol. 71, no. 12, pp. 1133-1143, 2013.

[27] F. Kamarudin, A. M. Nassir, M. H. Yahya, R. M. Said, and B. A. A. Nordin, "Islamic banking sectors in Gulf cooperative council countries: analysis on revenue, cost and profit efficiency concepts," Journal of Economic Cooperation and Development, vol. 35, no. 2, pp. 1-42, 2014.

[28] K. Lee, Y. Chung, K. Han, and T. Song, "Development and validation of privacy concern measurement tool in personal medical information," KIPS Transactions on Computer and Communication Systems, vol. 3, no. 6, pp. 197-208, 2014.

[29] C.-W. Park and J.-W. Kim, "An empirical research on information privacy concern in the IoT era," Journal of Digital Convergence, vol. 14, no. 2, pp. 65-72, 2016.

[30] H. I. Hussain, F. Kamarudin, H. M. T. Thaker, and M. A. Salem, “Artificial neural network to model managerial timing decision: non-linear evidence of deviation from target leverage," International Journal of Computational Intelligence Systems, vol. 12, no. 2, pp. 1282-1294, 2019.

[31] A. da Veiga, "Concern for information privacy in South Africa: an empirical study using the OIPCI," in Proceedings of the Paper Presented at the International Information Security Conference, Maribor, Slovenia, May 2020.

[32] M. S. Horswill and M. E. Coster, "The effect of vehicle characteristics on drivers' risk-taking behaviour," Ergonomics, vol. 45, no. 2, pp. 85-104, 2002.

[33] A. Puri, A Survey of Unmanned Aerial Vehicles (UAV) for Traffic Surveillance, Department of computer science and engineering, University of South Florida, Tampa, FL, USA, 2005.

[34] A. Barón and P. Green, "Safety and usability of speech interfaces for in-vehicle tasks while driving: a brief literature review," Technical Report UMTRI-2006-5, p. 31, University of Michigan, Transportation Research Institute, Ann Arbor, MI, USA, 2006.

[35] T. Willke, P. Tientrakool, and N. Maxemchuk, "A survey of inter-vehicle communication protocols and their applications," IEEE Communications Surveys \& Tutorials, vol. 11, no. 2, pp. 3-20, 2009.

[36] H. I. Hussain, S. Kot, S. Kot, and F. Kamarudin, "The nexus of competition freedom and the efficiency of microfinance institutions," Journal of Competitiveness, vol. 12, no. 2, pp. 67-89, 2020.
[37] P. Mun, J. Ohlsson, M. Ohlsson, I. Skog, and E. Nygren, "Smartphone-based measurement systems for road vehicle traffic monitoring and usage-based insurance," IEEE Systems Journal, vol. 8, no. 4, pp. 1238-1248, 2014.

[38] L. Uden and W. He, "How the Internet of Things can help knowledge management: a case study from the automotive domain," Journal of Knowledge Management, vol. 21, no. 1, pp. 57-70, 2017.

[39] M. Chen, Y. Tian, G. Fortino, J. Zhang, and I. Humar, "Cognitive internet of vehicles," Computer Communications, vol. 120 , pp. 58-70, 2018.

[40] Y. Ni, L. Cai, J. He et al., "Toward reliable and scalable internet of vehicles: performance analysis and resource management," Proceedings of the IEEE, vol. 108, no. 2, pp. 324-340, 2020.

[41] H. Zhang, J. Liu, H. Zhao, P. Wang, and N. Kato, "Blockchainbased trust management for internet of vehicles," IEEE Transactions on Emerging Topics in Computing, pp. 1-121, 2020.

[42] X. Shi, A. Dini, Z. Shao, N. H. Jabarullah, and Z. Liu, "Impacts of photovoltaic/wind turbine/microgrid turbine and energy storage system for bidding model in power system," Journal of Cleaner Production, vol. 226, pp. 845-857, 2019.

[43] N. A. Shafai, A. M. Nassir, F. Kamarudin, N. A. Rahim, and N. H. Ahmad, "Dynamic panel model of dividend policies: Malaysian perspective," Contemporary Economics, vol. 13, no. 3, pp. 239-252, 2019.

[44] N. H. Jabarullah, M. S. Shabbir, M. Abbas, A. F. Siddiqi, and S. Berti, "Using random inquiry optimization method for provision of heat and cooling demand in hub systems for smart buildings," Sustainable Cities and Society, vol. 47, Article ID 101475, 2019.

[45] B. Osatuyi, "Empirical examination of information privacy concerns instrument in the social media context," AIS Transactions on Replication Research, vol. 1, pp. 1-14, 2015.

[46] H. J. Smith, S. J. Milberg, and S. J. Burke, "Information privacy: measuring individuals' concerns about organizational practices," MIS Quarterly, vol. 20, no. 2, pp. 167-196, 1996.

[47] R. P. Bagozzi, "The nature and causes of self-esteem, performance, and satisfaction in the sales force: a structural equation approach," The Journal of Business, vol. 53, no. 3, pp. 315-331, 1980.

[48] J. F. Hair, R. E. Anderson, B. J. Babin, and W. C. Black, Multivariate Data Analysis: A Global Perspective, vol. 7, Pearson, Upper Saddle River, NJ, USA, 2010.

[49] C. Fornell and D. F. Larcker, Structural Equation Models with Unobservable Variables and Measurement Error: Algebra and Statistics, pp. 382-388, Sage Publications, Los Angeles, CA, USA, 1981. 